\title{
Molecular Characterization of Entomopathogenic Fungal Isolates
}

\author{
S. Sumaiya Parveen ${ }^{1 *}$, K. Ramaraju ${ }^{2}$ and S. Jeyarani ${ }^{2}$ \\ ${ }^{1}$ Karunya Institute of Technology and Sciences, Coimbatore, India \\ ${ }^{2}$ Tamil Nadu Agricultural University, Coimbatore, India \\ *Corresponding author
}

A B S T R A C T

K e y w o r d s
Entomopathogenic
fungi, Molecular
identification,
Beauveria bassiana,
Metarhizium
flavoviride var.
minus

Two most virulent local isolates, Beauveria bassiana (Bb 111) and Metarhizium flavoviride var. minus (Mf) were amplified using ITS1 and ITS4 primers. The amplified product length was approximately $600 \mathrm{bp}$ in both isolates. The nucleotide sequences of the isolates viz., B. bassiana $(\mathrm{Bb}$ 111 ) and $M$. flavoviride var. minus (Mf) deposited in the GenBank and were allotted with the accession numbers, KR 139926 and KR 139927, respectively.

\section{Introduction}

A great number of insects are always threatening crops of economic importance such as maize, wheat, soybean, etc. They may affect plants either directly by causing mechanical damages throughout feeding, or indirectly by transmitting and spreading plant pathogens such as viruses, mollicutes, and other bacteria. However, pesticides are not the best alternative of control, among other things, because of their undesirable effect upon the environment, altering ecological features. In addition, insects usually develop resistance to chemical pesticides, leading in some cases to the use of chemical pesticides more frequently and at higher concentrations, which might worsen the problem (23). Based on the negative effects of pesticides and the fact that sustainable agriculture requires better strategies to maintain insect populations under threshold values, biological control appears to be a potential tool for controlling insects. Entomopathogenic fungi might be a useful tool to develop an Integrated Pest Management program. The use of entomopathogenic fungi as a microbialcontrol agent was considered for the first time at the 
end of the 19th century, and the idea was widely accepted among researchers at a time when synthetic chemical insecticides were still unknown. However, the highest number of studies was carried out during the 20th century $(3,4,9)$. Since then, fungi have been found to have certain advantages over other methods of controls because they have restricted host range and are harmless to nontarget organisms such as predators, parasites, and other pathogens(11-13, 15,21).

Fungal isolates from different locations will have varying virulence and adaptability to environmental conditions like temperature and humidity. Utilization of native strains of entomopathogens with greater virulence and increased persistence in the environment are need of the hour. Identification and characterization of such type of isolates will pave way for the development of biopesticides with high virulence and temperature adaptability.

Several methods have been used to identify a species of entomopathogenic fungi. Hyphomycetes are classified by themorphological characteristics of spores, conidiogenous cells and colonies, their hosts, pathogenicity and growth or nutrient requirements [15]. Obviously, it is not quite possible to distinguish fungal isolates using only morphological characters. In recent years, molecular identification techniques are required as well as the traditional morphological characteristics. Different molecular techniques were used to identify a species of entomopathogenic fungi [11,1619].

\section{Materials and Methods}

The fungal pathogens, $\mathrm{Bb} 111$ and $M$. flavoviride var. minus isolated during the survey were morphologically identified as $B$. bassiana and M. flavoviride var. minus. To confirm the molecular level of identity, the two fungal pathogens $\mathrm{Bb} 111$ and $M$. flavoviride var minus were designated as $\mathrm{Bb}$ 111 and $\mathrm{Mf}$ and further investigations were made based on the internal transcribed spacer (ITS) region.

\section{DNA extraction}

For the isolation of DNA, the fungus was grown in $100 \mathrm{ml}$ SMAY broth and incubated for seven days. The mycelial mat was removed carefully and washed with sterile water repeatedly to remove the media constituents. 3 to $5 \mathrm{~g}$ of wet mycelium was freeze dried in $-70^{\circ} \mathrm{C}$ and ground in liquid nitrogen, followed by addition of 5 to $6 \mathrm{ml}$ of cetyl trimethyl ammonium bromide (CTAB) extraction buffer (10 mM tris-base ( $\mathrm{pH} 8.0)$, $20 \mathrm{mM}$ ethylene diamine tetra acetic acid (EDTA) (pH 8.0), $1.4 \mathrm{M} \mathrm{NaCl}$, CTAB (2\%), mercapto ethanol $(0.1 \%)$ and PVP $(0.2 \%)$. After that $20 \mu \mathrm{l}$ of proteinase $\mathrm{K}(20 \mathrm{mg} / \mathrm{ml})$ was added and incubated at $65^{\circ} \mathrm{C}$ for $1 \mathrm{~h}$. This was followed by addition of $20 \mu \mathrm{l}$ RNase A $(10 \mathrm{mg} / \mathrm{ml})$ and further incubated at $65^{\circ} \mathrm{C}$ for 15 minutes. To the supernatant collected after centrifugation (8,000 rpm, 10 minutes), 10 $\mu 1$ chloroform: iso amyl alcohol (24:1) was added.

The mixture was vortexed for 5 minutes and centrifuged at 12,000 rpm for 15 minutes. The supernatant was transferred to clean tube and mixed with equal volume of ice cold isopropanol. It was incubated at $25^{\circ} \mathrm{C}$ for DNA precipitation. The precipitate was collected by centrifugation and the pellet was washed with $0.1 \mathrm{M}$ ammonium acetate in 70 per cent ethanol.

Again incubation was given for 15 minutes to dry the pellet. The pellet was resuspended in TE buffer (10 mM Tris, 1mM EDTA, $\mathrm{pH}$ 8.0) and the DNA concentration was estimated spectrophotometrically. 
PCR amplification and sequencing of $18 \mathrm{~S}$ rRNA, ITS1, 5.8S r RNA, ITS2 and $28 S$ rRNA region

Polymerase chain reaction (PCR) amplification of $18 \mathrm{~S}$ ribosomal RNA was performed using primers of the internal transcribed spacer (ITS) region (White et al., 1990).

The primers used was

ITS1-F 5'- TCGGTAGGTAGGTGAACCT GCGG -3'

\section{8s-ITSRV1-R 5'- TCCTCCGCTTATTGAT ATGC -3'}

The polymerase chain reaction $(50 \mu \mathrm{l})$ was set to amplify the $18 \mathrm{~S}$ rRNA region by using the genomic DNA as template. The reaction mixture typically contained genomic DNA 20 to $40 \mathrm{ng}, 1 \mathrm{X}$ PCR reaction buffer $2.50 \mu \mathrm{l}, 2.5$ $\mathrm{mM}$ dNTPs $1.0 \mu \mathrm{l}$, forward and reverse primers 100ng each, and 3 unit of Taq DNA polymerase and finally the volume was made up to $50 \mu \mathrm{l}$ using distilled water. All the additions were done on ice and the PCR reaction was performed on gradient Mastercycler (Eppendorf, Germany). The PCR conditions for 18S rRNA amplification were initial denaturation at $94^{\circ} \mathrm{C}$ for $3 \mathrm{~min}$; followed by 35 cycles of $94^{\circ} \mathrm{C}$ for $1 \mathrm{~min}$, $56^{\circ} \mathrm{C}$ for $30 \mathrm{sec}, 72^{\circ} \mathrm{C}$ for $1 \mathrm{~min}$ and final extension at $72^{\circ} \mathrm{C}$ for $10 \mathrm{~min}$. The PCR products were resolved by electrophoresis in a 1.5 per cent agarose gel, visualized under UV light and photographed and documented with an Alpha Imager. The PCR products were sequenced following Sanger sequencing chemistry using universal primer pair and sequencing work has been done at SciGenom Labs Private Ltd., Kerala.

To confirm the identity of strain $B$. bassiana (Bb 111) and M. flavoviride var. minus (Mf) and to investigate their phylogenetic relationship with other strains from different geographical region, partial sequence of $18 \mathrm{~S}$ rRNA ITS1-5.8s-ITS4-28s region of the two strains were obtained as detailed above and compared with ten nearest homologous search in GenBank of NCBI database following BLAST analysis and the phylogenetic tree was constructed using Neighbour joining analysis. To identify the intra geographic variation and host specificity, further $B$. bassiana (Bb 111) and M. flavoviride var. minus (Mf) strain was compared with sequences of indigenous B. bassiana and $M$. flavoviride strains downloaded from genbank. Nucleotide sequence alignments were made using CLUSTALW2 with the multiple alignment parameters. Phylogenetic tree was constructed and the sequential agglomerative hierarchical non overlapping clustering was done using unweighted pair groups with arithmetic averages (UPGMA) method.

The correct identity of the isolates viz., $\mathrm{Bb}$ 111 as B. bassiana and $\mathrm{Mf}$ as M. flavoviride var, minus was confirmed through $B$. bassiana and $M$. flavoviride var. minus through molecular methods (ITS region analysis). Similar conformity studies for $B$. bassiana and M. flavoviride var. minus were documented by several workers (Shih et al., 1995; Coates et al., 2001; Kim et al., 2008). In the present study, amplification of internal transcribed spacer region (ITS) of B. bassiana (Bb 111) and $M$. flavoviride var. minus isolates with ITS 1 and ITS 4 primers revealed that both isolates were amplified at approximately $600 \mathrm{bp}$ and was confirmed with identity of other $B$. bassiana and $M$. flavoviride var. minus (Fig 1 \&2).

The results are in accordance with the findings of Neuveglise et al., (1994), De Muro et al., (2012) and Sabbahi et al., (2012) where they differentiated the Beauveria 
isolates by targeting $28 \mathrm{~S}$ rDNA sequences as well 18S rRNA, ITS regions and 5.8S of $\mathrm{r}$ DNA. De Muro et al., (2012) followed combination of different techniques to differentiate isolates of Beauveria species collected from litter material and insect samples. They also found that isolates having high similarity at morphological observation were also found to show similarity with ITS sequence analysis. Similar studies with ITS 5.8S- ITS2 sequence analysis were conducted in different continents to study the genetic diversity of $B$. bassiana isolates (Ghikas et al., 2010; Bhana et al., 2011).

Fig.1 Characterization of B. bassiana (Bb 111) based on ITS region

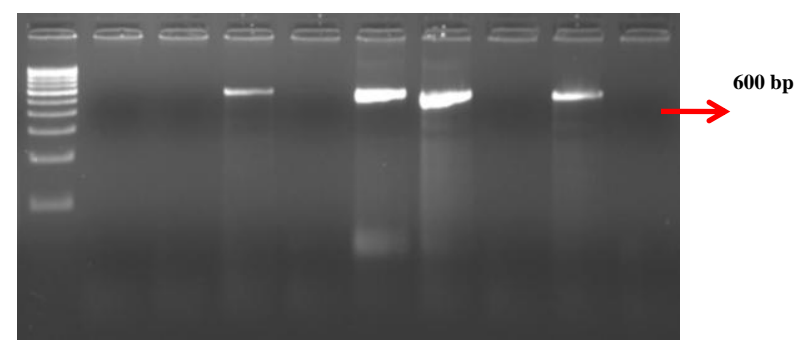

Fig.2 Characterization of M. flavoviride var. minus based on ITS region

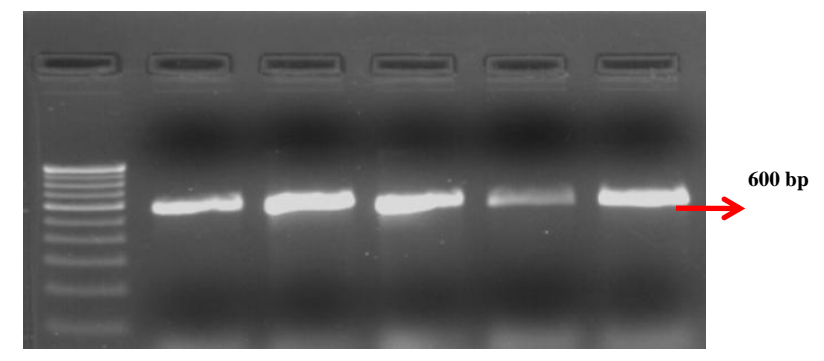

In conclusion, identification and detailed description of the fungal strain as an active ingredient of biopesticide is required environmental and epizootiologial information. In this study, we conducted a molecular study of entomopathogenic fungi isolated from the plants. Additional research is required to test pathogenicity of these fungi to other pests and to determine the effectiveness in the field conditions.

\section{Acknowledgement}

The authors thankfully acknowledge the Department of Biotechnology (DBT), New Delhi, for financial support to conduct the experiments.

\section{References}

1. Aquino De Muro A., Elliott S., Moore D, Parker B L. and Skinner M., Molecular characterization of Beauveria bassiana isolates obtained from overwintering sites of Sunn Pests (Eurygaster and Aelia species). Mycological Research, 109, 294306 (2005)

2. Bhana, N.M., G.V. Cron, V.M. Gray and C.J. Straker., The placement of South African strains of Beauveria in Phylogeny inferred from rDNA ITS-5.8S-ITS2 sequences. J. Gen. Appl. Microbiol., 57, 269-276(2011)

3. Burges HD., Microbial control of pests and plant diseases, Academic Press 
(1981).

4. Cantwell G.E., Pathogenesis of invertebrate microbial diseases, Allanheld Osmun Publications, (1974)

5. Castrillo L.A., Brooks W.M., Differentiation of Beauveria bassiana isolates from the darkling beetle, Alphitobius diaperinus, using isozyme and RAPD analyses, J. Invertebr. Pathol, 72, 190-196 (1998)

6. Coates, B.S., Hellmich R.L. and Lewis L. Beauveria bassiana haplotype determination based on nuclear rDNA internal transcribed spacer PCR-RFLP. Mycol. Res., 106, 40-50 (2001)

7. De Muro M.A., Elliot S., Moore D., Parker B.L., Skinner M., Reid M. and Bouhssini M.E., Molecular characterisation of Beauveria bassiana isolates obtained from overwintering sites of sunn Pests (Eurygaster and Aelia species). Mycol. Res., 109 (3), 294306(2012)

8. Estrada M.E., Camacho M.V., Benito C., "The molecular diversity of different isolates of Beauveria bassiana (Bals.) Vuill. as assessed using intermicrosatellites (Issrs)". Cellular and Molecular Biology Letters,12,240- 252 (2007)

9. Ferron P., Fungal Control, In: KerkutGA, Gilbert LI, Editors. Comprehensive insect physiology, biochemistry and pharmacology, Pergamon Press, 313346(1985)

10. Ghikas D.V., Kouvelis V.N. and Typas, M.A., Phylogenetic and biogeographic implications inferred by mitochondrial intergenic region analyses and ITS1-5.8SITS2 of the entomopathogenic fungi Beauveria bassiana and $B$. brongniartii. BMC Microbiology, 10:174(2010).

11. Goettel M.S., Hajek A.E., Siegel J.P., Evans H.C., Safety of Fungal Biocontrol Agents. In: Butt T, Jackson C, Magan N, Editors. Fungal Biocontrol Agents -
Progress, Problems and Potential, CABBI Press, 347-375 (2001).

12. Goettel M.S., Hajek A.E., Evaluation of nontarget effects of pathogens used for management of arthropods. In: Wajnberg E., Scott J.K., Quimy P.C., Editors. Evaluating Indirect Ecological Effects of Biological Control, CABBI Press, 81-97 (2001)

13. Goettel M.S., Poprawski T.J., Vandenverg J.D., Li Z. and Roberts D.W., Safety to non-target invertebrates of fungal biocontrol agents. In: Laird M., Lacey L.A., Davidson E.W., Editors. Safety of Microbial Insecticides, CRC Press, 209232 (1990)

14. Kim J. S., Roh J.Y., Choi Y., Shin S.C., Jeon M.J., and Je Y. H., Identification of an entomopathogenic fungus, Beauveria bassiana SFB-205 toxic to the green peach aphid, Myzus persicae. J. Indust. Entomol., 17(2), 211-215 (2008).

15. Lacey L.A., Goettel M.S., Current developmentsin microbial control of insect pestsand prospects for the early $21^{\text {st }}$ century. Entomophaga40, 3-27(1995)

16. Neuveglise C., Brygoo Y., Vercambre, B. and Riba G., Comparative analysis of molecular and biological characteristics of strains of Beauveria brongniartii isolated from insects. Mycol. Res.,98, 322 - 328 (1994)

17. Sabbahi R., Lavallee R., Merzouki, A. and Guertin, C., Differentiation of entomopathogenic fungus Beauveria bassiana (Ascomycetes: Hypocreales) isolates by PCR-RFLP. Phytoprotection, 90, 49-56(2012)

18. Samson R.A., "Identification Entomopathogenic Deuteromycetes. In: Microbial Control of Pests and PlantsDiseases (Ed: Burges H. D.), 19701980. Acad. Press, London, 93-106, (1981)

19. Sevim A., Demir I., Hofte M., Humber R.A., Demirbag Z., "Isolation and 
characterization of entomopathogenic fungi from hazelnut-growing region of Turkey", BioControl,55(2), 279-297, (2010)

20. Shih, H. L., Lin C.P., Liou R.F. and Tzean, S.S., Complete nucleotide sequence of Beauveria bassiana 5.8s rRNA coding gene and flanking internal transcribed spacers. DNA Seq., 5: 381-383 (1995)

21. Vestergaard S., Cherry A., Keller S. and Goettel M., Hyphomycete fungi as microbial control agents. In: Hokkanen H.M.T., Hajek A.E., Editors. Environmental Impacts of Microbial
Insecticides, Kluwer Academic Publishers, 35-62 (2003)

22. Wang C.S., Li Z.Z., Butt T.M., Molecular studies of co-formulated strains of the entomopathogenic fungus, Beauveria bassiana. J. Invertebr. Pathol.,80, 29-34 (2002).

23. Watkins P.R., Huesing J.E., Margam V., Murdock L.L. and Higgins T.J.V., Insects, nematodes, and other pests. In: Altman A, Hasegawa PM, Editors. Plant Biotechnology and Agriculture Prospects for the 21st Century. Elsevier Inc., 353-370 (2012).

\section{How to cite this article:}

Sumaiya Parveen, S., K. Ramaraju and Jeyarani, S. 2020. Molecular Characterization of Entomopathogenic Fungal Isolates. Int.J.Curr.Microbiol.App.Sci. 9(07): 2588-2593. doi: https://doi.org/10.20546/ijcmas.2020.907.305 